\title{
Differentiation of 'Candidatus Phytoplasma cynodontis' Based on 16S rRNA and groEL Genes and Identification of a New Subgroup, 16SrXIV-C
}

J. Mitrović and M. Smiljković, Laboratory of Applied Phytopathology, Institute of Pesticides and Environmental Protection, Belgrade, Serbia; Erich Seemüller, Julius Kuehn Institute, Federal Research Centre for Cultivated Plants, Institute for Plant Protection in Fruit Crops and Viticulture, Dossenheim, Germany; Richard Reinhardt and Bruno Hüttel, Max Planck Genome Centre Cologne, Köln, Germany; Carmen Büttner, Department of Crop and Animal Sciences, Humboldt-Universität zu Berlin, Berlin, Germany; Assunta Bertaccini, DipSA, Plant Pathology, Alma Mater Studiorum, University of Bologna, Bologna, Italy; Michael Kube, Department of Crop and Animal Sciences, HumboldtUniversität zu Berlin, Berlin, Germany; and Bojan Duduk, Laboratory of Applied Phytopathology, Institute of Pesticides and Environmental Protection, Belgrade, Serbia

\begin{abstract}
Mitrović, J., Smiljković, M., Seemüller, E., Reinhardt, R., Hüttel, B., Büttner, C., Bertaccini, A., Kube, M., and Duduk, B. 2015. Differentiation of 'Candidatus Phytoplasma cynodontis' based on 16S rRNA and groEL genes and identification of a new subgroup, 16SrXIV-C. Plant Dis. 99:1578-1583.

'Candidatus Phytoplasma cynodontis' is widespread in bermudagrass and has only been found in monocotyledonous plants. Molecular studies carried out on strains collected in Italy, Serbia, and Albania enabled verification of molecular variability in the $16 \mathrm{~S}$ ribosomal RNA (rRNA) gene. Based on restriction fragment length polymorphism and sequence analyses, the strains from Serbia were clearly differentiated from all others and assigned to a new ribosomal DNA (rDNA) subgroup designated as 16SrXIV-C. A system for amplification of fragments containing the ' $\mathrm{Ca}$. P. cynodontis' groEL gene was developed to enable study of its variability in related strains belonging to different $16 \mathrm{SrXIV}$ subgroups. Despite the fact that the groEL gene exhibited a greater sequence

variation than $16 \mathrm{~S}$ rRNA, the phylogenetic tree based on groEL gene sequence analysis was highly congruent with the $16 \mathrm{~S}$ rDNA-based tree. The groEL gene analyses supported differentiation of the Serbian strains and definition of the new subgroup 16SrXIV-C. Phylogenetic analyses of both genes confirmed distinct phylogenetic lineages for strains belonging to $16 \mathrm{SrXIV}$ subgroups. Furthermore, groEL is the only nonribosomal marker developed for characterization of ' $\mathrm{Ca}$. $\mathrm{P}$. cynodontis' thus far, and its application in molecular surveys should provide better insight into the relationships among these phytoplasmas and correlation between strain differentiation and their geographical distribution.
\end{abstract}

Bermudagrass white leaf (BGWL) is a disease of bermudagrass (Cynodon dactylon (L.) Pers.) associated with 'Candidatus Phytoplasma cynodontis' and transmitted by the leafhopper Exitianus capicola (Marcone et al. 2004; Salehi et al. 2009). Typical symptoms of BGWL include extensive chlorosis, proliferation of axillary shoots, bushy growing habit, small leaves, shortened stolons and rhizomes, stunting, and plant death (Marcone et al. 2004). 'Ca. P. cynodontis' (BGWL phytoplasma) has been reported to have the smallest genome, with a size of $530 \mathrm{kbp}$, among all studied self-replicating organisms, estimated by pulsed-field gel electrophoresis, and is specifically associated with infection of monocotyledonous plants (Marcone et al. 2004). Therefore, its characterization may be important to studies of phytoplasma genome evolution and gene variability.

' $\mathrm{Ca}$. P. cynodontis' belongs to the BGWL group (16SrXIV), which consists of subgroups 16SrXIV-A (Lee et al. 1998) and 16SrXIV-B, recently described in Iran (Salehi et al. 2009). The disease was reported for the first time in Taiwan in 1972 and has been reported since then throughout Asia, Africa, Australia, and Europe, and in Cuba (Arocha et al. 2005; Chen et al. 1972; Dafalla and Cousin 1988; Marcone et al. 1997; Salehi et al. 2009; Sdoodee

Corresponding author: B. Duduk; E-mail: bojan.duduk@pesting.org.rs

GenBank accession numbers of DNA sequences: KF383978, KF383979, KF383980, KF383981, KF383982, KF383983, KF383984, KF383985, KJ000021, KJ000022, KJ000023, KJ000024, KP019339, KP019340, KP019341, and KP019342.

*The $\boldsymbol{e}$-Xtra logo stands for "electronic extra" and indicates that one supplementary figure is published online.

Accepted for publication 29 April 2015.

http://dx.doi.org/10.1094/PDIS-01-15-0061-RE

(c) 2015 The American Phytopathological Society et al. 1999; Viswanathan 1997; Zahoor et al. 1995). Although BGWL is a widespread disease, little is known about sequence variations in ' $C a$. P. cynodontis' genes other than $16 \mathrm{~S}$ ribosomal DNA (rDNA), which has shown some variability. Phylogenetic analyses of $16 \mathrm{~S}$ rDNA sequences have indicated that BGWL phytoplasma strains, together with Brachiaria and Cynodon white leaf phytoplasmas, form a discrete subclade within the phytoplasma clade, having some distinct lineages also within the BGWL subclade (Çağlar et al. 2013; Marcone et al. 2004; Salehi et al. 2009). Phytoplasma classification was established using the properties of the $16 \mathrm{~S}$ rDNA but it does not always provide molecular distinction of closely related strains. Because of the conserved nature of the $16 \mathrm{~S}$ ribosomal RNA (rRNA) gene, more variable single-copy genes, such as ribosomal protein (rpl22 and rpS3), secY, tuf, and groEL have been employed for finer differentiation of other phytoplasmas (Lee et al. 2004, 2006, 2010; Marcone et al. 2000; Martini et al. 2007; Mitrović et al. 2011); however, corresponding information is not available for ' $\mathrm{Ca}$. P. cynodontis'. The 16S-23S rDNA spacer region has been found highly conserved among different BGWL strains, while the $\sec A$ gene has been used only for diagnostic purposes (Bekele et al. 2011; Marcone et al. 2004).

In the present study, we identified a new subgroup (16SrXIV-C) of ' $C a$. P. cynodontis' and developed a groEL gene polymerase chain reaction (PCR) assay, which we used, in addition to $16 \mathrm{~S}$ rDNA and the 16S-23S rDNA spacer regions, for differentiation of ' $\mathrm{Ca}$. $\mathrm{P}$. cynodontis'-related strains from three European countries.

\section{Materials and Methods}

Sample collection and nucleic acid extraction. Eight bermudagrass samples exhibiting BGWL symptoms (leaf whitening, small leaves, bushy growing, and stunting) were collected from the following locations: two samples from mowed lawns on two locations in Italy; one sample from a park in an urban area in Tirana, Albania; and five samples from mowed lawns on three locations in public parks in Serbia (Table 1). Total nucleic acid was extracted from $0.5 \mathrm{~g}$ of symptomatic leaves following a previously described protocol (Doyle and Doyle 1990), then 
resuspended in Tris-EDTA buffer and stored at $-20^{\circ} \mathrm{C}$. Nucleic acids were diluted 25- to 100 -fold in sterile distilled water to obtain a DNA concentration of $20 \mathrm{ng} / \mu \mathrm{l}$, before performing PCR assays.

Primer design. Two sequences obtained in a genomic survey and available online (GenBank accession numbers KF437623 and KF437624), containing partial groEL sequences of BGWL phytoplasma, were used for primer design. The sequence KF437623 containing the 3' end of the groES, groES-groEL spacer region and the $5^{\prime}$ end of the groEL gene, and the sequence KF437624 containing the $3^{\prime}$ end of the groEL gene, together enabled the design of primers that specifically amplify the DNA fragment containing the groEL gene of BGWL phytoplasma. A forward primer was designed inside the groES gene while two reverse primers were designed on and near the $3^{\prime}$ end of the groEL gene. The forward primer CYNgroesF2 (5'-ACTATTCCGGAACTCAAT-3') was based on a sequence starting 89 bp upstream of the $3^{\prime}$ end of groES, while the reverse primers CYNgroelR (5'-TATAAAGAAGAAG

Table 1. 'Candidatus Phytoplasma cynodontis' strains and accession numbers of their 16S ribosomal DNA (rDNA) and groEL gene sequences

\begin{tabular}{|c|c|c|c|c|}
\hline Locality & Sampling year & Strain & Accession numbers for $16 \mathrm{~S}$ rDNA, groEL ${ }^{\mathrm{a}}$ & Ribosomal subgroup \\
\hline Montemassi, Italy & 2010 & IT71/10 & KF383979 $(1,768)$, KF383983 $(1,687)$ & 16SrXIV-A \\
\hline Belgrade-Zvezdara, Serbia & 2011 & RS59/11 & KF383981 (1,755), KF383985 $(1,748)$ & 16SrXIV-C \\
\hline Tirana, Albania & 2011 & AL85/11 & KF383980 (1,764), KF383984 $(1,725)$ & 16SrXIV-A \\
\hline Tormancina, Italy & 2012 & IT35/12 & KF383978 (1,749), KF383982 $(1,718)$ & 16SrXIV-A \\
\hline Jarak, Serbia & 2013 & RS123/13 & KJ000024 (1,748), KJ000022 (1,748) & 16SrXIV-C \\
\hline Belgrade-Zemun, Serbia & 2013 & RS306/13 & KJ000021 (1,729), KJ000023 (1,748) & 16SrXIV-C \\
\hline Belgrade-Zemun, Serbia & 2013 & $\mathrm{RS} 305 / 13$ & KP019340 (1,755), KP019342 (1,709) & 16SrXIV-C \\
\hline Belgrade-Zemun, Serbia & 2013 & RS304/13 & KP019339 (1,763), KР019341 $(1,709)$ & 16SrXIV-C \\
\hline
\end{tabular}

${ }^{a}$ Length in base pairs of obtained sequences is given in parentheses

Table 2. Bermudagrass white leaf (BGWL) phytoplasmas and related strains used as representatives for phylogenetic analyses

\begin{tabular}{|c|c|c|c|c|}
\hline Strain $^{\mathbf{a}}$ & Geographic origin & GenBank $^{\mathbf{b}}$ & Host & Reference \\
\hline BGWL-C1 & Italy & AJ550984 & Cynodon dactylon & Marcone et al. 2004 \\
\hline M4 & Turkey & HE599391 & C. dactylon & Çağlar et al. 2013 \\
\hline FBGWL & Iran & EF444485 & C. dactylon & Salehi et al. 2009 \\
\hline JBGWL & Iran & EF444486 & C. dactylon & Salehi et al. 2009 \\
\hline BGWL3 & Thailand & AF248961 & C. dactylon & Davis and Dally 2001 \\
\hline BGWL-Di.sa & India & GQ403689 & Digitaria sanguinalis & Rao et al. 2010 \\
\hline BGWL-Op.bu & India & GQ403690 & Oplismenus burmannii & Rao et al. 2010 \\
\hline CWL & Australia & AF509321 & C. dactylon & Blanche et al. 2003 \\
\hline GBGWL & Myanmar & AB741630 & C. dactylon & Win et al. 2013 \\
\hline GBGWL2 & Myanmar & AB642601 & Chrysopogon acicalatus & Win and Jung 2012 \\
\hline BraWL-KK & Thailand & AB052872 & Brachiaria sp. & Jung et al. 2003 \\
\hline Gorakhpur & India & EU032485 & Cynodon dactylon & Snehi et al. 2008 \\
\hline $\mathrm{KF}-\mathrm{C} 1$ & China & EU377477 & C. dactylon & Unpublished \\
\hline
\end{tabular}

${ }^{\mathrm{a}} \mathrm{CWL}=$ Cynodon white leaf phytoplasma and BraWL $=$ Brachiaria white leaf phytoplasma.

b GenBank accession numbers for $16 \mathrm{~S}$ ribosomal DNA.

16SrXIV-A
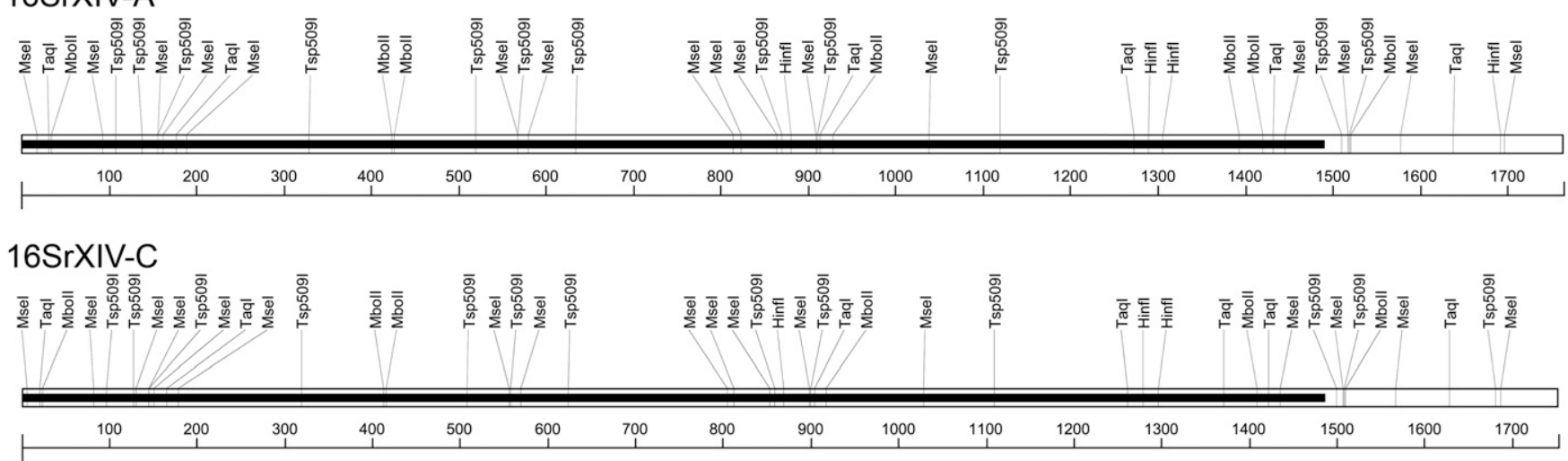

16SrXIV-B

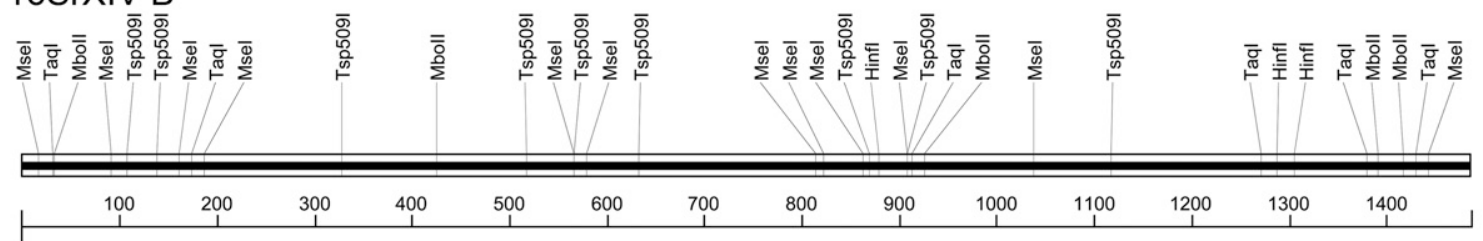

Fig. 1. Restriction maps showing positions of restriction sites in $16 \mathrm{~S}$ ribosomal DNA (marked by black bar) and 16S-23S spacer region sequences of strains BGWL-C1, RS59/11, and JBGWL, the reference strains of 16SrXIV-A, - C, and -B ribosomal subgroups, respectively. Msel and Trul are isoschizomers of each other. 
GATCG-3') and CYNgroelR2 (5'-ACACTACTGCTGCTCCT-3') were based on a sequence ending 1 and 56 bp upstream, respectively, of the $3^{\prime}$ end of the groEL gene. The expected PCR product sizes were approximately 1,800 bp for CYNgroesF2/CYNgroelR and $1.7 \mathrm{kbp}$ for CYNgroesF2/CYNgroelR2 primer pairs.

PCR and restriction fragment length polymorphism analyses. PCR assays with the universal phytoplasma primer pair P1/P7 (Deng and Hiruki 1991; Schneider et al. 1995) and the primer pairs developed in this study, CYNgroesF2/CYNgroelR and CYNgroesF2/CYNgroelR2, were performed to amplify the BGWL phytoplasma $16 \mathrm{~S}$ rDNA and partial groEL gene, respectively. Each $25-\mu 1$ PCR reaction mix contained $1 \mu \mathrm{l}$ of diluted template DNA, $1 \times$ PCR Master Mix (Fermentas, Vilnius, Lithuania), and $0.4 \mu \mathrm{M}$ each primer. Asymptomatic bermudagrass samples and reaction mixes lacking DNA were employed as negative controls. Thirty-five amplification cycles were performed under described conditions (Deng and Hiruki 1991), except that a $56^{\circ} \mathrm{C}$ annealing temperature was used for the CYNgroesF2/CYNgroelR2 primer pair. PCR products $(6 \mu \mathrm{l})$ were separated by electrophoresis in $1 \%$ agarose gel, stained with ethidium bromide, and visualized with a UV transilluminator.

Restriction fragment length polymorphism (RFLP) analyses of P1/P7 amplicons were performed using the HinfI, TaqI, MboII,
Tsp509I, and Tru1I restriction enzymes (Fermentas) under conditions described by the manufacturer. All restriction products were separated by electrophoresis in $8 \%$ polyacrylamide gel and stained and visualized as described above.

Sequence analyses. Direct P1/P7-amplified products of $16 \mathrm{~S}$ rDNA and CYNgroesF2/CYNgroelR, or CYNgroesF2/CYNgroelR2 of groEL, were purified using the mi-PCR purification kit (Metabion International AG, Martinsried, Germany). The P1/P7 amplicons were sequenced in both directions with primers P1, R16F2n (Gundersen and Lee 1996), P7, and 350R (Namba et al. 1993), while the CYNgroesF2/CYNgroelR amplicons were sequenced with the same primers used for amplification. For sequencing of the CYNgroesF2/CYNgroelR2 amplicons, in addition to the primers used for amplification, two primers, forward CYNgelFseq (5'-TACAAAGTGTTAATTCAGAC-3') and reverse CYNgelRseq (5'-GCTCCCATATTGTGATAAGG-3'), were used for sequencing to cover the complete amplicon. Sequencing was performed by a commercial service (Macrogen Inc.). The obtained sequences were assembled using Pregap4 from the Staden program package (Staden et al. 1999) and deposited in the National Center for Biotechnology Information (NCBI) under accession numbers listed in Table 1 .

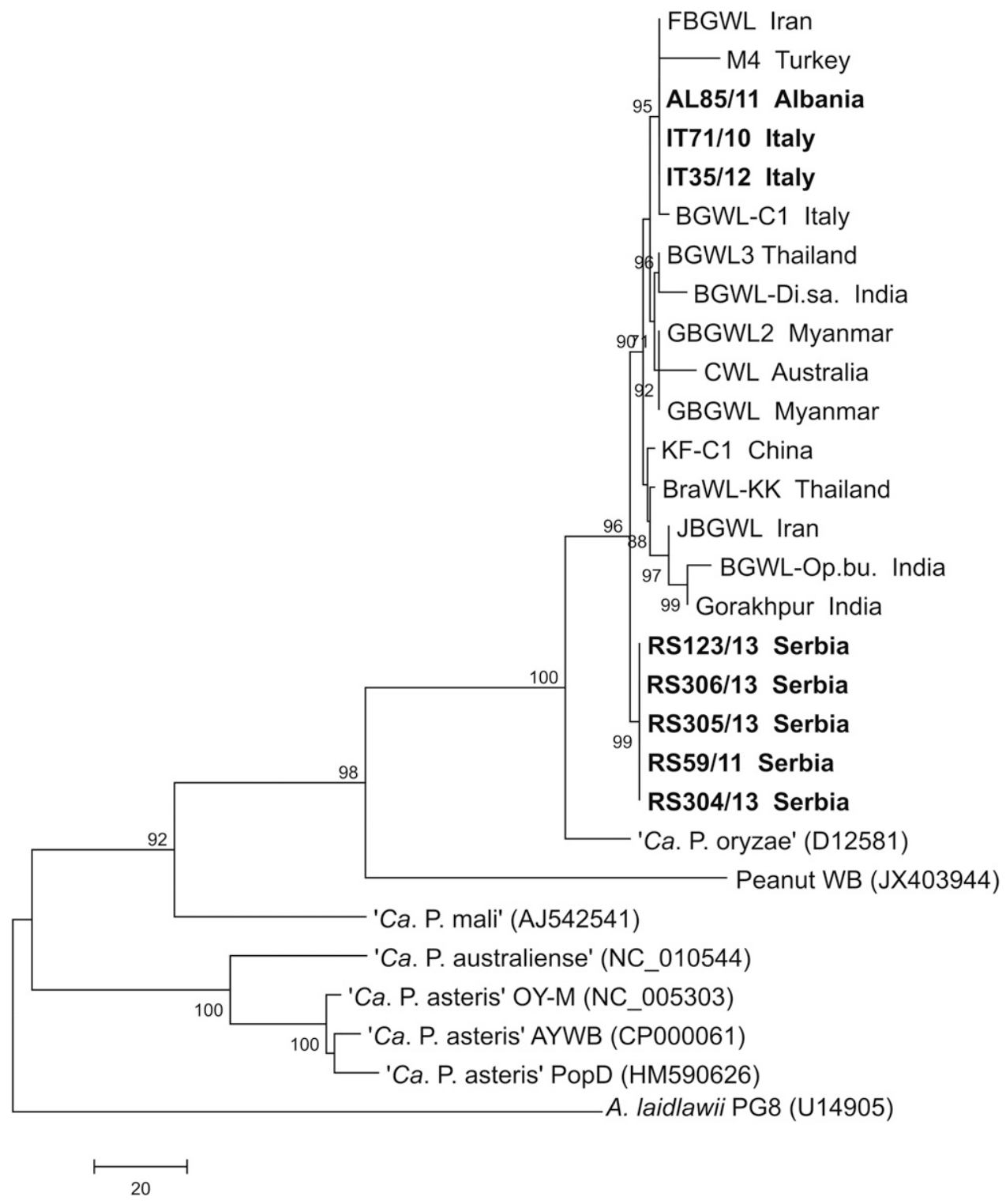

Fig. 2. Phylogenetic tree constructed by parsimony analyses of $16 \mathrm{~S}$ ribosomal DNA sequences of 21 'Candidatus Phytoplasma cynodontis' and 7 other 'Ca. Phytoplasma' strains, employing Acholeplasma laidlawii as outgroup. One of nine equally parsimonious trees is shown. Numbers on the branches are bootstrap values obtained for 1,000 replicates (only values above $70 \%$ are shown). Strains obtained and analyzed in this work are in bold. 
The 16S rDNA sequences were aligned using Clustal W (Larkin et al. 2007) from the Molecular Evolutionary Genetics Analysis program MEGA6 (Tamura et al. 2013) and a search for single-nucleotide polymorphisms (SNP) was performed in the Bioedit program (Hall 1999). The 16S rDNA sequences of strains BGWL-C1 and JBGWL (GenBank accession numbers AJ550984 and EF444486, respectively), representing the $16 \mathrm{SrXIV}-\mathrm{A}$ and -B subgroups, respectively, were added to the alignment, and putative restriction site maps were generated using MapDraw (DNASTAR Inc.).

Evolutionary history was inferred based on the 16S rDNA of BGWL strains sequenced in this work and 12 other representatives of BGWL phytoplasma available in the NCBI using the maximum parsimony (MP) method (MEGA6). The 12 representatives of BGWL and related phytoplasmas were selected according to their geographical origin and are listed in Table 2. Additional sequences of ' $C a$. P. oryzae' (Liefting et al. 1996) (GenBank accession number D12581), 'Ca. P. mali' (Seemüller and Schneider, 2004) (GenBank accession number AJ542541), 'Ca. P. australiense' (Tran-Nguyen et al. 2008) (GenBank accession number NC_010544), representatives of ' $\mathrm{Ca}$. P. asteris' (Bai et al. 2006; Mitrović et al. 2011; Oshima et al. 2004) (GenBank accession number NC_005303, CP000061, and HM590626), and peanut witches' broom phytoplasma (Chung et al. 2013) (GenBank accession number JX403944) were retrieved and included in the analyses. Acholeplasma laidlawii strain PG8 (Artiushin et al. 1995) (GenBank accession number U14905) was designated as the outgroup to root the tree. The MP tree was obtained using the Close-Neighbor-Interchange algorithm with search level 5 , in which initial trees were obtained with the random addition of sequences (10 replicates). The "Gaps/Missing Data Treatment" option was set to "use all sites". To estimate the statistical significance of the inferred clades, 1,000 bootstraps were performed to estimate the stability and support for the inferred clades.

The obtained groEL gene sequences of the eight European BGWL phytoplasmas studied were aligned with six other phytoplasma groEL gene sequences available in the NCBI (' $\mathrm{Ca}$. P. asteris' strains AYWB, OY-M, and PopD; ' $C a$. P. australiense'; ' $C a$. P. mali'; and peanut witches' broom phytoplasma strain NTU2011) and the evolutionary history was inferred as described above, together with evolutionary history based on $16 \mathrm{~S}$ rDNA for comparison.

\section{Results}

Analyses of 16S rDNA. The 16S rDNA and the partial spacer region of all tested BGWL phytoplasma strains were successfully amplified using the $\mathrm{P} 1 / \mathrm{P} 7$ primer pair, confirming the presence of phytoplasma DNA. The sequences obtained from P1/P7 amplicons ranged from 1,729 to 1,768 bp and contained the $16 \mathrm{~S}$ rDNA and $16 \mathrm{~S}-23 \mathrm{~S}$ rDNA spacer region. The search for SNP revealed no differences at any nucleotide position among the strains from Italy and Albania and showed the highest homology with the 16S rDNA sequence of ' $C a$. P. cynodontis' reference strain BGWL-C1 (GenBank accession number AJ550984), confirming their identification as ' $\mathrm{Ca}$. P. cynodontis', ribosomal subgroup 16SrXIV-A. In contrast, the five sequenced Serbian strains were identical to each other but different from all others. The Serbian strains showed 11 nucleotide differences from the other European strains, of which 8 were in the 16S rDNA and 3 in the 16S-23S rDNA spacer region. Compared with JBGWL (GenBank accession number EF444486), the reference strain of 16SrXIV-B, the Serbian strain and other European BGWL strains showed 10 and 8 SNP in $16 \mathrm{~S}$ rDNA, respectively. The $16 \mathrm{~S}$ rDNA sequence of ribosomal subgroup 16SrXIV-C (strain RS 59/11) was 99.37 and $99.33 \%$ similar to the corresponding sequences of subgroups 16SrXIV-A (strain IT71/10) and 16SrXIV-B (strain JBGWL), respectively. The $16 \mathrm{~S}$ rDNA sequences of ribosomal subgroups 16SrXIV-A and 16SrXIV-B (strains IT71/10 and JBGWL) were $99.46 \%$ similar.

Virtual RFLP analyses indicated that five restriction enzymes (HinfI, TaqI, MboII, Tsp509I, and Tru1I) can differentiate the Serbian strains from all other European strains tested that belong to subgroup 16SrXIV-A, while the Serbian strains were also differentiated from strains in subgroup 16SrXIV-B (Fig. 1). The differential restriction sites for TaqI, MboII, and Tru1I restriction enzymes are located in the 16S rRNA gene, fulfilling conditions for description of the new ribosomal subgroup 16SrXIV-C. For confirmation, the obtained P1/P7 amplicons of the Serbian strains and IT71/10 (representative of subgroup 16SrXIV-A) were subjected to RFLP analyses with the five restriction enzymes. The Serbian strains showed identical profiles with all restriction enzymes used (data not shown). Three restriction profiles (HinfI, TaqI, and MboII) of the Serbian strain were different when compared with the corresponding restriction profiles of 16SrXIV-A BGWL strain, while the differences in Tsp509I and Tru1I restriction profiles, visible in virtual RFLP analyses, were hardly or not at all visible in the polyacrylamide gel run after RFLP reaction.

The phylogenetic tree derived by MP analysis of the 16S rRNA gene sequences showed that the analyzed ' $\mathrm{Ca}$. P. cynodontis' strains formed a well-supported (bootstrap value of 96\%) phylogenetic

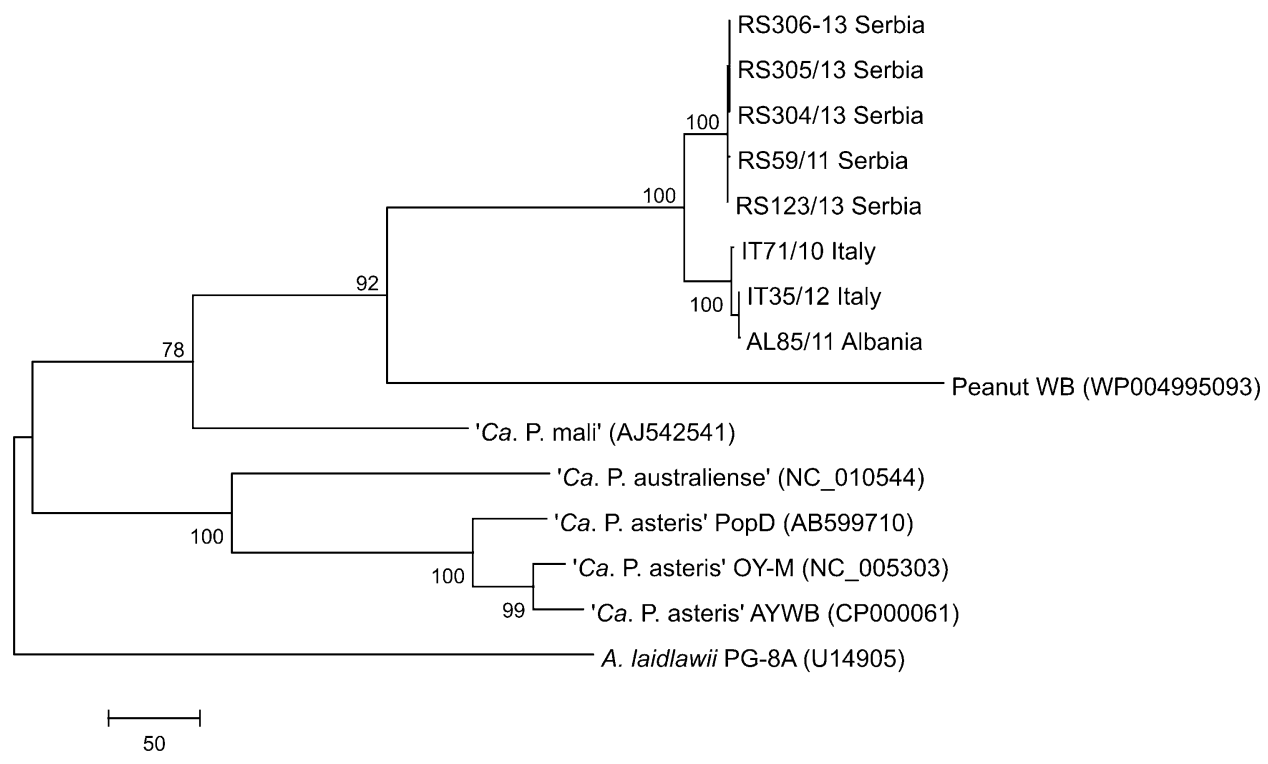

Fig. 3. Phylogenetic tree constructed by parsimony analyses of the groEL gene sequences of eight 'Candidatus Phytoplasma cynodontis' and other available 'Ca. Phytoplasma' strains, employing Acholeplasma laidlawii as outgroup. One of six equally parsimonious trees is shown. Numbers on the branches are bootstrap values obtained for 1,000 replicates (only values above $70 \%$ are shown) 
group closely related to ' $\mathrm{Ca}$. P. oryzae' (Fig. 2). Interestingly, the Serbian strains formed a well-supported (bootstrap value of 99\%) separate lineage from the other ' $\mathrm{Ca}$. P. cynodontis' strains.

Analyses of groEL gene. Using the CYNgroesF2/CYNgroelR primer pair in direct PCR assays, amplicons of approximately 1.8 $\mathrm{kb}$ were obtained with the two Italian and one Albanian BGWL phytoplasma strains employed, while no amplification with Serbian strains was obtained (data not shown). When the CYNgroesF2/CYNgroelR2 primer pair was used in direct PCR, amplicons of approximately 1.7 $\mathrm{kb}$ were obtained with all eight BGWL phytoplasma strains (data not shown). The three sequences obtained from CYNgroesF2/CYNgroelR and five sequences from CYNgroesF2/CYNgroelR2 amplicons ranged from 1,687 to 1,748 bp containing the $3^{\prime}$ end of groES gene, groESgroEL spacer region, and most of the groEL gene. The search for SNP revealed no differences at any nucleotide position between strains IT35/12 and AL85/11 from Italy and Albania, respectively. Strain IT71/10, the other one from Italy, showed one nucleotide difference (position 1,236 of groEL $[\mathrm{C} / \mathrm{T}]$ ), synonymous when translated, from the other two strains from Italy and Albania. Serbian strains RS304/13, RS305/13, and RS306/13 were identical in the groEL gene and showed one nucleotide difference (position 687 of groEL $[\mathrm{C} / \mathrm{T}])$, synonymous when translated, from the other two Serbian strains (RS59/11 and RS123/13), which were identical. The Serbian and Italian or Albanian strains showed 3.0 to $3.1 \%$ differences in the groEL nucleotide and $1.7 \%$ of deduced amino acid sequences.

The phylogenetic tree derived by MP analysis of the groEL gene sequences showed that ' $\mathrm{Ca}$. P. cynodontis' strains formed a monophyletic group within the phytoplasma clade (Fig. 3). The ' $\mathrm{Ca}$. P. cynodontis' subclade position within the phytoplasma clade is congruent with its position according to the $16 \mathrm{~S}$ rDNA-derived phylogenetic tree (data not shown). The Serbian BWGL strains tested, as in case of $16 \mathrm{~S}$ rDNA, clustered separately from the other European 'Ca. P. cynodontis' strains analyzed.

\section{Discussion}

The obtained results confirm earlier reports that had associated the symptoms observed on bermudagrass plants in Europe with the presence of 'Ca. P. cynodontis' (Marcone et al. 1997), and present the first molecular characterization of ' $\mathrm{Ca}$. P. cynodontis' with a molecular marker other than 16S rDNA.

Sequence analyses of $16 \mathrm{~S}$ rDNA confirmed that the $16 \mathrm{SrXIV}$ ribosomal group is highly supported, with a bootstrap value of $96 \%$, and forms subclades within the ' $\mathrm{Ca}$. P. cynodontis' clade. Strains from Serbia formed a highly supported (bootstrap value of 99\%) distant lineage from all other BGWL phytoplasma strains analyzed in this study. The other cluster contains all other European strains, one strain each from Turkey and Iran, and the remaining BWGL strains from the Far East (China, India, Myanmar, Thailand, and Australia). The two Italian and Albanian strains clustered closest to the reference strain from Italy (BGWL-C1), previously described by Marcone et al. (2004). Based on the RFLP analyses of the 16S rRNA gene, the intergenic spacer region, and beginning of the $23 \mathrm{~S}$ ribosomal gene (P1/P7 amplicons), strains from Serbia were assigned to the ribosomal group $16 \mathrm{SrXIV}$, the BGWL group. The BGWL phytoplasma strains from Serbia were assigned to a new rDNA subgroup proposed to be named $16 \mathrm{SrXIV}-\mathrm{C}$ because their collective RFLP profiles differed from those of 16SrXIV-A strain (IT71/10), the virtual RFLP profiles differed from the other strains belonging to both 16SrXIV-A and -B subgroups (Lee et al. 1998; Salehi et al. 2009), and the differentiating restriction site positions were verified as located inside the $16 \mathrm{~S}$ rDNA gene. Phylogenetic analysis of the $16 \mathrm{~S}$ rRNA gene alone supported the assignment of Serbian strains to the new subgroup 16SrXIV-C. Moreover, phylogeny based on 16S rDNA showed some correlation with geographical origin, separating European and Turkish strains from the Far East strains and making Iran an area where both groups of strains are present.

Considering the limitations of $16 \mathrm{~S}$ rDNA in phylogenetic discrimination of closely related phytoplasma strains (Lee et al. 2006; Martini et al. 2007; Mitrović et al. 2011) and aiming to further evaluate usefulness of the groEL gene, specific primers for groEL gene amplification of all tested BGWL phytoplasmas were successfully developed and employed. The results suggest that, in agreement with previous work on other phytoplasma groups (Mitrović et al. 2011), groEL also may be used as an additional marker gene for BGWL phytoplasmas after additional testing has been performed on other BGWL strains, including strains in the subgroup 16SrXIV-B.

The comparative sequence analyses conducted on groEL and $16 \mathrm{~S}$ rDNA sequences substantiated the data obtained through RFLP and sequence analyses of the $16 \mathrm{~S}$ rRNA gene. Furthermore, the groEL gene exhibited a greater sequence variation than $16 \mathrm{~S}$ rDNA among the tested BGWL phytoplasma strains. In particular, considering the strains which were identical regarding the $16 \mathrm{~S}$ rDNA, groEL revealed one nucleotide difference (synonymous when translated) in sequences of three strains from the Serbian group (RS304/13, RS305/13, and RS306/13) and one from Italy (IT71/10), whereas the Serbian strains showed more differences from other European strains in the groEL gene nucleotide sequence than in $16 \mathrm{~S}$ rDNA (3.0 to $3.1 \%$ compared with $0.54 \%$ ). These results are in agreement with data already reported for the groEL gene in aster yellows phytoplasma strain differentiation (Mitrović et al. 2011). The phylogenetic tree based on groEL gene sequence analysis was highly congruent with the 16S rDNA-based tree and confirmed distinct phylogenetic lineages among the BGWL phytoplasma strains analyzed. One lineage contains the strains from Italy and Albania (IT71/10, IT35/12, and AL85/11), while strains from Serbia (RS59/11, RS123/13, RS304/13, RS305/13, and RS306/13) formed a separate lineage. This separation of the two groups of strains is strongly supported by high bootstrap values. Because $g r o E L$ is the only nonribosomal marker developed for BGWL phytoplasmas thus far, its further application in molecular surveys of non-European strains, including those assigned to subgroup 16SrXIV-B, should give a better insight into the relationships among BGWL phytoplasmas and correlation between differentiation and geographic distribution of their strains.

\section{Acknowledgments}

This work was funded as a grant from the project TR31043 of the Serbian Ministry of Education, Science, and Technological Development and supported by the German Research Foundation (DFG projects KU 2679/2-1 and BU 890/21-1), Max-Planck Society, and bilateral project of the German Academic Exchange Service (DAAD) 56266384 and the Serbian Ministry of Education, Science, and Technological Development 451-02-00446/2013-09/11.

\section{Literature Cited}

Arocha, Y., Horta, D., Piñol, B., Palenzuela, I., Picornell, B., Almeida, R., and Jones, P. 2005. First report of a phytoplasma associated with Bermuda-grass white leaf disease in Cuba. Plant Pathol. 54:233.

Artiushin, S., Duvall, M., and Minion, F. C. 1995. Phylogenetic analysis of mycoplasma strain ISM1499 and its assignment to the Acholeplasma oculi strain cluster. Int. J. Syst. Bacteriol. 45:104-109.

Bai, X., Zhang, J., Ewing, A., Miller, S. A., Jancso Radek, A., Shevchenko, D. V., Tsukerman, K., Walunas, T., Lapidus, A., Campbell, J. W., and Hogenhout, S. A. 2006. Living with genome instability: The adaptation of phytoplasmas to diverse environments of their insect and plant hosts. J. Bacteriol. 188:3682-3696.

Bekele, B., Abeysinghe, S., Hoat, T. X., Hodgetts, J., and Dickinson, M. 2011. Development of specific secA-based diagnostics for the 16SrXI and 16SrXIV phytoplasmas of the Gramineae. Bull. Insectol. 64:S15-S16.

Blanche, K. R., Tran-Nguyen, L. T. T., and Gibb, K. S. 2003. Detection, identification and significance of phytoplasmas in grasses in northern Australia. Plant Pathol. 52:505-512.

Çăglar, B. K., Satar, S., and Elbeaino, T. 2013. Detection and molecular characterization of Bermuda grass (Cynodon dactylon) white leaf phytoplasma from Turkey. Int. J. Agric. Biol. 15:90-94.

Chen, T. C., Lee, C. S., and Chen, M. J. 1972. Mycoplasmalike organisms in Cynodon dactylon and Brachiaria distachya affected by white leaf disease. Rep. Taiwan Sugar Exp. Stn. 56:49-55.

Chung, W. C., Chen, L. L., Lo, W. S., Lin, C. P., and Kuo, C. H. 2013. Comparative analysis of the peanut witches'-broom phytoplasma genome reveals horizontal transfer of potential mobile units and effectors. PLoS One 8:E62770.

Dafalla, G. A., and Cousin, M.-T. 1988. Fluorescence and electron microscopy of Cynodon dactylon affected with a white leaf disease in Sudan. J. Phytopathol. 122:25-34.

Davis, R. E., and Dally, E. L. 2001. Revised subgroup classification of group $16 \mathrm{SrV}$ phytoplasmas and placement of flavescence dorée-associated phytoplasmas in two distinct subgroups. Plant Dis. 85:790-797.

Deng, S., and Hiruki, C. 1991. Amplification of 16S rRNA genes from culturable and nonculturable Mollicutes. J. Microbiol. Methods 14:53-61. 
Doyle, J. J., and Doyle, J. L. 1990. Isolation of plant DNA from fresh tissue. Focus 12:13-15.

Gundersen, D. E., and Lee, I.-M. 1996. Ultrasensitive detection of phytoplasmas by nested-PCR assays using two universal primer pairs. Phytopathol. Mediterr. 35:144-151.

Hall, T. A. 1999. BioEdit: A user-friendly biological sequence alignment editor and analysis program for Windows 95/98/NT. Nucleic Acids Symp. Ser. 41: 95-98

Jung, H.-Y., Sawayanagi, T., Wongkaew, P., Kakizawa, S., Nishigawa, H., Wei, W., Oshima, K., Miyata, S., Ugaki, M., Hibi, T., and Namba, S. 2003. 'Candidatus Phytoplasma oryzae', a novel phytoplasma taxon associated with rice yellow dwarf disease. Int. J. Syst. Evol. Microbiol. 53:1925-1929.

Larkin, M. A., Blackshields, G., Brown, N. P., Chenna, R., McGettigan, P. A., McWilliam, H., Valentin, F., Wallace, I. M., Wilm, A., Lopez, R., Thompson, J. D., Gibson, T. J., and Higgins, D. G. 2007. Clustal W and Clustal X version 2.0. Bioinformatics 23:2947-2948.

Lee, I.-M., Gundersen-Rindal, D. E., Davis, R. E., and Bartoszyk, I. M. 1998. Revised classification scheme of phytoplasmas based on RFLP analyses of $16 \mathrm{~S}$ rRNA and ribosomal protein gene sequences. Int. J. Syst. Bacteriol. 48:1153-1169.

Lee, I.-M., Martini, M., Marcone, C., and Zhu, S. F. 2004. Classification of phytoplasma strains in the elm yellows group (16SrV) and proposal of 'Candidatus Phytoplasma ulmi' for the phytoplasma associated with elm yellows. Int. J. Syst. Evol. Microbiol. 54:337-347.

Lee, I.-M., Zhao, Y., and Bottner, K. D. 2006. SecY gene sequence analysis for finer differentiation of diverse strains in the aster yellows phytoplasma group. Mol. Cell. Probes 20:87-91.

Lee, I.-M., Zhao, Y., and Davis, R. E. 2010. Prospects of multiple gene-based systems for differentiation and classification of phytoplasmas. Pages 51-62 in: Phytoplasmas: Genomes, Plant Hosts and Vector. P. Weintraub and P. Jones, eds. CAB International, Wallingford, UK.

Liefting, L. W., Andersen, M. T., Beever, R. E., Gardner, R. C., and Forster, R. S. 1996. Sequence heterogeneity in the two 16S rRNA genes of phormium yellow leaf phytoplasma. Appl. Environ. Microb. 62:3133-3139.

Marcone, C., Lee, I.-M., Davis, R. E., Ragozzino, A., and Seemüller, E. 2000. Classification of aster yellows-group phytoplasmas based on combined analyses of rRNA and tuf gene sequences. Int. J. Syst. Evol. Microbiol. 50: 1703-1713.

Marcone, C., Ragozzino, A., and Seemüller, E. 1997. Detection of Bermuda grass white leaf disease in Italy and genetic characterization of the associated phytoplasma by RFLP analysis. Plant Dis. 81:862-866.

Marcone, C., Schneider, B., and Seemüller, E. 2004. 'Candidatus Phytoplasma cynodontis', the phytoplasma associated with Bermuda grass white leaf disease. Int. J. Syst. Evol. Microbiol. 54:1077-1082.

Martini, M., Lee, I.-M., Bottner, K. D., Zhao, Y., Botti, S., Bertaccini, A., Harrison, N. A., Carraro, L., Marcone, C., Khan, A. J., and Osler, R. 2007. Ribosomal protein gene-based phylogeny for finer differentiation and classification of phytoplasmas. Int. J. Syst. Evol. Microbiol. 57:2037-2051.

Mitrović, J., Kakizawa, S., Duduk, B., Oshima, K., Namba, S., and Bertaccini, A. 2011. The groEL gene as an additional marker for finer differentiation of 'Candidatus Phytoplasma asteris'-related strains. Ann. Appl. Biol. 159:41-48.
Namba, S., Kato, S., Iwanami, S., Oyaizu, H., Shiozawa, H., and Tsuchizaki, T. 1993. Detection and differentiation of plant-pathogenic mycoplasmalike organisms using polymerase chain reaction. Phytopathology 83:786-791.

Oshima, K., Kakizawa, S., Nishigawa, H., Jung, H. Y., Wei, W., Suzuki, S., Arashida, R., Nakata, D., Miyata, S., Ugaki, M., and Namba, S. 2004. Reductive evolution suggested from the complete genome sequence of a plant-pathogenic phytoplasma. Nat. Genet. 36:27-29.

Rao, G. P., Mall, S., and Marcone, C. 2010. 'Candidatus Phytoplasma cynodontis' (16SrXIV group) affecting Oplismenus burmannii (Retz.) P. Beauv. and Digitaria sanguinalis (L.) Scop. in India. Australas. Plant Dis. Notes 5:93-95.

Salehi, M., Izadpanah, K., Siampour, M., and Taghizadeh, M. 2009. Molecular characterization and transmission of bermuda grass white leaf phytoplasma in Iran. J. Plant Pathol. 91:655-661.

Schneider, B., Seemüller, E., Smart, C. D., and Kirkpatrick, B. C. 1995. Phylogenetic classification of plant pathogenic mycoplasmalike organisms or phytoplasmas. Pages 369-380 in: Molecular and Diagnostic Procedures in Mycoplasmology. S. Razin and J. G. Tully, eds. Academic Press, San Diego, CA.

Sdoodee, R., Schneider, B., Padovan, A., and Gibb, K. S. 1999. Detection and genetic relatedness of phytoplasmas associated with plant diseases in Thailand. J. Biochem. Mol. Biol. Biophys. 3:133-140.

Seemüller, E., and Schneider, B. 2004. 'Candidatus Phytoplasma mali', 'Candidatus Phytoplasma pyri' and 'Candidatus Phytoplasma prunorum', the causal agents of apple proliferation, pear decline and European stone fruit yellows, respectively. Int. J. Syst. Evol. Microbiol. 54:1217-1226.

Snehi, S. K., Khan, M. S., Raj, S. K., Mall, S., Singh, M., and Rao, G. P. 2008. Molecular identification of 'Candidatus Phytoplasma cynodontis' associated with Bermuda grass white leaf disease in India. Plant Pathol. 57:770.

Staden, R., Beal, K. F., and Bonfield, J. K. 1999. The Staden package, 1998. Pages 115-130 in: Methods in Molecular Biology, Vol. 132: Bioinformatics Methods and Protocols. S. Misener and S. A. Krawetz, eds. Humana Press Inc. Totowa, NJ.

Tamura, K., Stecher, G., Peterson, D., Filipski, A., and Kumar, S. 2013. MEGA6: Molecular evolutionary genetics analysis version 6.0. Mol. Biol. Evol. 30: 2725-2729.

Tran-Nguyen, L. T., Kube, M., Schneider, B., Reinhardt, R., and Gibb, K. S. 2008 Comparative genome analysis of 'Candidatus Phytoplasma australiense' (subgroup tuf-Australia I; rp-A) and ' $\mathrm{Ca}$. Phytoplasma asteris' Strains OY-M and AY-WB. J. Bacteriol. 190:3979-3991.

Viswanathan, R. 1997. Detection of phytoplasmas associated with grassy shoot disease of sugarcane by ELISA techniques. J. Plant Dis. Prot. 104:9-16.

Win, N. K. K., and Jung, H. Y. 2012. 'Candidatus Phytoplasma cynodontis' associated with white leaf disease of golden beard grass (Chrysopogon acicalatus). Trop. Plant Pathol. 37:76-79.

Win, N. K. K., Kim, Y. H., Jung, H. Y., and Ohga, S. 2013. Molecular characterization of white leaf phytoplasma associated with the Graminae in Myanmar. J. Fac. Agric. Kyushu Univ. 58:225-229.

Zahoor, A., Bashir, M., Nakashima, K., Mitsueda, T., and Murata, N. 1995. Bermuda grass white leaf caused by phytoplasmas in Pakistan. Pak. J. Bot. 27:251-252. 